\title{
Short stature and gestational diabetes in Brazil
}

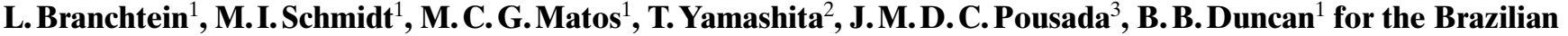 \\ Gestational Diabetes Study Group* \\ ${ }^{1}$ School of Medicine, Federal University of Rio Grande do Sul, Porto Alegre, Brazil \\ ${ }^{2}$ São Paulo State Public Servants Hospital, São Paulo, Brazil \\ ${ }^{3}$ School of Medicine, Federal University of Bahia, Salvador, Brazil
}

\section{Abstract}

Aims/hypothesis. To examine the association between maternal stature and gestational diabetes mellitus.

Methods. We studied a sample of 5564 consecutive Brazilian women 20 or more years old, who were pregnant for approximately 21-28 weeks, had no history of diabetes outside pregnancy and were attending general prenatal care units in six state capitals in Brazil from 1991 to 1995 . We did a 2-h, 75-g oral glucose tolerance test, defining gestational diabetes by World Health Organisation criteria.

Results. Those in the shortest quartile of height $(\leq 151 \mathrm{~cm})$ had a $60 \%$ increase in the odds of having gestational diabetes, independently of prenatal clinic, age, global obesity, family history of diabetes, skin colour, referral pattern, waist circumference, parity, previous gestational diabetes, education, ambient temperature and gestational age compared with the tallest quartile [odds ratio $(\mathrm{OR})=1.60, p=0.005$ ]. This association was observed for those with above median values of skinfold thickness $(\mathrm{OR}=1.74$, $p=0.006$ ) but not for those with below median values ( $\mathrm{OR}=1.22, p=0.51)$. Associations of short stature with high 2 -h glycaemia $(\geq 7.8 \mathrm{mmol} / \mathrm{l})(\mathrm{OR}=1.61$, $p=0.005)$ were essentially the same as those for gestational diabetes. There was, however, no association between short stature and gestational hyperglycaemia when the latter was defined exclusively by fasting values $(\mathrm{OR}=0.97, p=0.90)$.

Conclusion/interpretation. In Brazil short stature associates with gestational diabetes, principally in women with greater fat mass. This difference in glycaemic levels is present postprandially but not in the fasting state. [Diabetologia (2000) 43: 848-851]

Keywords Gestational diabetes, pregnancy, stature, obesity, risk factors, undernourishment.
An association between adult short stature and Type II (non-insulin-dependent) diabetes mellitus has been reported previously [1,2]. More recently, short stature has also been related to gestational diabetes (GDM) in Korea and Greece [3, 4].

To further evaluate the independence and magnitude of the relation between short stature and gesta-

\footnotetext{
* see Acknowledgements

Received: 11 January 2000 and in revised form: 20 March 2000

Corresponding author: L. Branchtein, MD, r. Itaboraí, 54/602, Porto Alegre, RS, 90670030 Brazil

Abbreviations: GDM, Gestational diabetes mellitus; WHO, World Health Organisation; OR, odds ratio.
}

tional diabetes, we investigated this association in 4973 women participating in the Brazilian Gestational Diabetes Study. We also examined whether the association occurs in both the fasting and post-load state and its variability across strata of adiposity.

\section{Subjects and methods}

The study was conducted in general prenatal care units in six state capitals in Brazil, from 1991 to 1995 . A total of 5564 consecutive pregnant women aged 20 or more years with no diagnosis of diabetes outside pregnancy and who were approximately 21-28 weeks pregnant were enrolled. The Brazilian population can be divided for epidemiological purposes in three main groups: white (descendants of Europeans), black 
(descendants of Africans) and mixed (descendants of a mixture of Europeans, Africans and native Brazilians). Native Brazilians and those of oriental descent are much less frequent. Because of small numbers, 25 women of these latter two groups were excluded; 566 were excluded due to incomplete data. Results pertain to the baseline data of the remaining 4973 women.

At enrolment, a standardised questionnaire was completed and anthropometric measurements were obtained in duplicate according to a standard protocol [5]. A standardised 2-h, 75-g oral glucose tolerance test (OGTT) was done according to the World Health Organisation (WHO) recommendations [6]. Fasting, 1-h and 2-h plasma glucose were measured using the glucose-oxidase method [7] in certified laboratories at each centre. Patients were informed of the nature of the study and consented to participate. Local institutional ethics committees approved the study protocol.

Gestational diabetes was defined according to the WHO, i.e., fasting $7.0 \mathrm{mmol} / \mathrm{l}$ or more and/or $2-\mathrm{h} 7.8 \mathrm{mmol} / \mathrm{l}$ or more [8]. Global adiposity was assessed by the sum of four skin-fold thicknesses (bicipital, tricipital, subscapular and suprailiac).

Odds of GDM were estimated through logistic regression models, height being the main exposure. Covariates were sequentially added to the models and their inclusion in final models was based on statistical significance $(p<0.05)$ of each covariate or their individual contribution to the change in magnitude of the association under study or both. Similar analyses were done separately in the two sample strata defined by the median sum of skin-folds.

Further models estimated odds of gestational hyperglycaemia when the condition was defined separately by a high glucose concentration at each moment of the OGTT, as follows: 2-h glycaemia $7.8 \mathrm{mmol} / \mathrm{l}$ or more, 1 -h $9.2 \mathrm{mmol} / \mathrm{l}$ or more and fasting $5.5 \mathrm{mmol} / \mathrm{l}$ or more, the latter two cut points representing the same centile as $7.8 \mathrm{mmol} / \mathrm{l}$ for 2 -h glycaemia.

Statistical analyses were done with the SPSS statistical package [9].

\section{Results}

The clinical and physical characteristics of the 4973 women studied are shown for the whole sample and separately for those in the lowest quartile $(\leq 151 \mathrm{~cm})$ and in the three remaining quartiles of height (Table 1). As expected, the shortest women were lighter and had smaller waist circumferences but the two height groups had similar body mass indices. Shorter women also tended more frequently to be of black skin colour, multiparous, with lower educational status, and less frequently to have a known family history of diabetes. Mean height $( \pm$ SD) for the whole sample is $155.7( \pm 6.5) \mathrm{cm}$.

Crude prevalences of gestational diabetes decreased with increasing maternal height (Fig.1). This inverse association is present for 1-h and 2-h glucose but not for fasting values (Fig. 2). Consistent with this finding, Pearson correlation coefficients for maternal height with fasting, 1-h and 2-h glucose concentrations were $-0.03(\mathrm{NS}),-0.08(p<0.001)$ and $-0.12(p<0.001)$, respectively.

Results of logistic regression analyses for the relation between quartiles of maternal height and gesta-
Table 1. Means $( \pm$ SD) and percentages for characteristics of study subjects

\begin{tabular}{|c|c|c|c|}
\hline & \multirow{2}{*}{$\begin{array}{l}\text { Whole sample } \\
(n=4973)\end{array}$} & \multicolumn{2}{|l|}{ Height } \\
\hline & & $\begin{array}{l}\leq 151 \mathrm{~cm} \\
(n=1238)\end{array}$ & $\begin{array}{l}>151 \mathrm{~cm} \\
(n=3735)\end{array}$ \\
\hline Age (years) & $27.8 \pm 5.5$ & $27.7 \pm 5.6$ & $27.9 \pm 5.4$ \\
\hline $\begin{array}{l}\text { Pre-pregnancy } \\
\text { Weight }(\mathrm{kg}) \\
\text { BMI }\left(\mathrm{kg} / \mathrm{m}^{2}\right)\end{array}$ & $\begin{array}{l}56.8 \pm 10.9 \\
23.4 \pm 4.1\end{array}$ & $\begin{array}{l}50.7 \pm 8.8 \\
23.3 \pm 3.9\end{array}$ & $\begin{array}{l}58.8 \pm 10.9 \\
23.4 \pm 4.1\end{array}$ \\
\hline Waist (cm) & $82.2 \pm 8.2$ & $80.0 \pm 7.5$ & $83.0 \pm 8.3$ \\
\hline Education (years) & $7.9 \pm 3.8$ & $6.8 \pm 3.6$ & $8.3 \pm 3.7$ \\
\hline $\begin{array}{l}\text { Parental history of } \\
\text { diabetes }\end{array}$ & $14.9 \%$ & $13.1 \%$ & $15.5 \%$ \\
\hline $\begin{array}{l}\text { Previous gestations } \\
\quad 0 \\
1 \\
\geq 2\end{array}$ & $\begin{array}{l}27.2 \% \\
26.8 \% \\
46.0 \%\end{array}$ & $\begin{array}{l}24.0 \% \\
25.4 \% \\
50.6 \%\end{array}$ & $\begin{array}{l}28.2 \% \\
27.3 \% \\
44.5 \%\end{array}$ \\
\hline $\begin{array}{l}\text { Skin colour } \\
\text { White } \\
\text { Mixed } \\
\text { Black }\end{array}$ & $\begin{array}{l}45.2 \% \\
13.7 \% \\
41.1 \%\end{array}$ & $\begin{array}{l}38.6 \% \\
10.0 \% \\
51.4 \%\end{array}$ & $\begin{array}{l}47.4 \% \\
14.9 \% \\
37.7 \%\end{array}$ \\
\hline
\end{tabular}

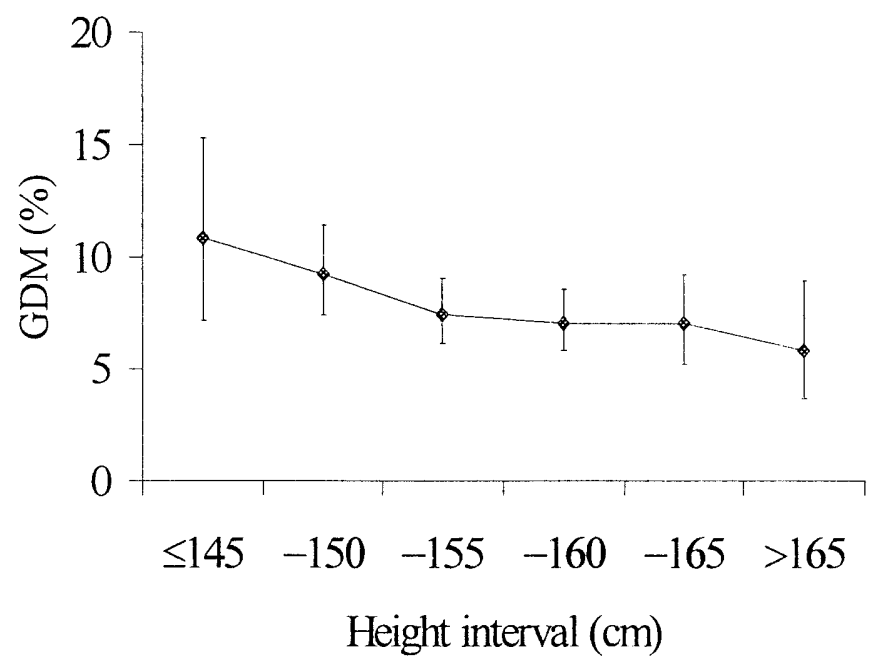

Fig. 1. Prevalence of gestational diabetes $( \pm 95 \% \mathrm{CI})$ according to intervals of maternal height $(n=4973)$

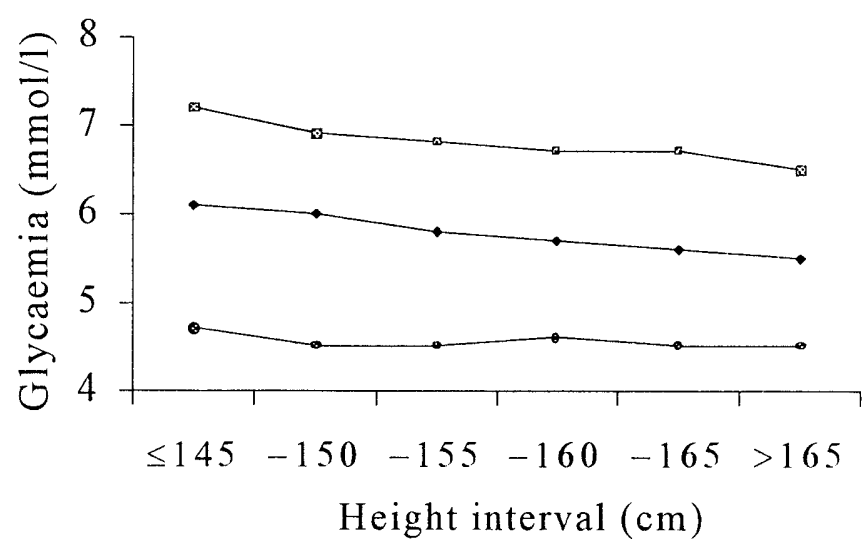

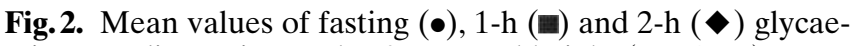
mia according to intervals of maternal height $(n=4973)$ 
Table 2. Odds ratios (OR) for the association between maternal height and gestational diabetes in the whole sample and stratified by global adiposity $(n=4973)^{\mathrm{a}}$

\begin{tabular}{|c|c|c|c|c|c|c|}
\hline \multirow{2}{*}{$\begin{array}{l}\text { Height } \\
\text { quartiles }(\mathrm{cm})\end{array}$} & \multicolumn{2}{|c|}{ Whole sample } & \multicolumn{2}{|c|}{ Leanest half } & \multicolumn{2}{|c|}{ Heaviest half } \\
\hline & $\overline{\mathrm{OR}}$ & $p$ & $\overline{\mathrm{OR}}$ & $p$ & $\overline{\mathrm{OR}}$ & $p$ \\
\hline & 1 & 0.00 & 12 & 0. & 1.74 & 0.006 \\
\hline & 1 & 0. & 0.8 & 0.70 & 1.18 & 0.40 \\
\hline $155.5 \mathrm{t}$ & 1.02 & 0.91 & 0.98 & 0.94 & 1.03 & 0.89 \\
\hline 160.0 to $183.4^{\mathrm{b}}$ & 1.00 & - & 1.00 & - & 1.00 & - \\
\hline
\end{tabular}

${ }^{a}$ Adjusting for prenatal clinic, age, global obesity, family history of diabetes, skin colour, referral pattern, waist circumference, parity, previous gestational diabetes, education, ambient temperature and gestational age.

${ }^{\mathrm{b}}$ Reference category

tional diabetes show that the shortest women $(\leq 151 \mathrm{~cm})$ had a $60 \%$ increase in the relative odds of having GDM, independently of prenatal clinic, age, global obesity, family history of diabetes, skin colour, referral pattern, waist circumference, parity, previous gestational diabetes, education, ambient temperature and gestational age, compared with the tallest quartile $(\mathrm{OR}=1.60,95 \% \mathrm{CI}=1.15-2.22)(\mathrm{Ta}-$ ble 2).

When we stratified the study subjects according to the median value of the sum of skin-fold thicknesses, this association remained significant only for the more obese (in lean: $\mathrm{OR}=1.22,95 \% \mathrm{CI}=0.67-2.24$; in obese: $\mathrm{OR}=1.74,95 \% \mathrm{CI}=1.17-2.59$ ).

We next examined gestational hyperglycaemia defined separately at each moment of the OGTT. Results for high 2 -h glycaemia ( $\geq 7.8 \mathrm{mmol} / \mathrm{l})$ were similar $(\mathrm{OR}=1.61,95 \% \mathrm{CI}=1.16-2.23, p=0.005)$ to those described above for GDM. High-fasting glycaemia ( $\geq 5.5 \mathrm{mmol} / \mathrm{l}$ ) showed, however, no association with maternal short stature $(\mathrm{OR}=0.97,95 \%$ $\mathrm{CI}=0.70-1.38, p=0.90)$. The association of maternal short stature with high 1 -h glycaemia $(\geq 9.2 \mathrm{mmol} / \mathrm{l})$ was of intermediate strength and of borderline significance $(\mathrm{OR}=1.37,95 \% \mathrm{CI}=0.97-1.92, p=0.07)$.

\section{Discussion}

Our results confirm previous observations in Korean and Greek women $[3,4]$ that maternal short stature is independently associated with gestational diabetes.

In our sample, the shortest women presented the least favourable socio-economic indicators; they had poorer educational status and were more frequently of black skin colour. This might suggest that the major cause of short stature in these women was fetal or early childhood undernourishment or both. Inadequate intake of calories or protein or both represent the most common cause of failure to grow worldwide [10]. Thus, according to the "thrifty phenotype" hypothesis $[11,12]$, the same adaptative alterations that protected these women from undernourishment during their early development could have led them to short stature, as well as to glucose intolerance, in this study assessed by gestational diabetes.

Alternatively, it is possible that a genetically determined insulin effect could lead to both failure to grow and to diabetes $[13,14]$. In this case, the short stature seen could be a reflection of the so-called "thrifty genotype" [15-17], that contributed to survival of our ancestors and now predisposes an important fraction of the current generation of Brazilian women to gestational diabetes.

In this study, the association between short stature and GDM was observed only among women with above-median fat mass, as estimated by skin-fold thicknesses. This finding corroborates similar observations in several studies. One showed that adult men whose weight in the first year of life was below the median and whose present body mass index (BMI) was above the median tended more frequently to have impaired glucose tolerance and diabetes than the other subjects [18]. In a cohort of 70-year-old men, only those in the highest tertile of BMI showed an association between low birth weight and poor insulin sensitivity [19]. Similar results were described in 7-year-old children with low birth weight. Those among them who had gained more weight during childhood had higher post-load insulin concentrations [20]. The sum of these results support the hypothesis that it is principally when the "thrifty" metabolism is associated with later excess weight gain that it leads to impaired glucose tolerance and diabetes.

We also observed that the 2-h, post-load but not fasting glycaemia was related to short stature. These results corroborate previously published, but not discussed findings about the relation of adult height or fetal exposure to famine with glycaemic and insulinaemic levels $[1,3,21]$. An inverse correlation between height and 2-h, post-load glycaemia, but none between height and fasting glycaemia in adults has been shown in the United Kingdom [1]. The same was described in pregnant Korean women; a negative association of height with 3-h, post-load but not with fasting glycaemia and insulinaemia [3]. Also, adults exposed to famine in the Netherlands during the prenatal period similarly presented higher 2 -h, post-load but not fasting glycaemia and insulinaemia [21].

Differences in prognostic relevance of fasting and post-load glycaemia have received great attention recently, with epidemiological studies suggesting considerably greater prognostic value for post-load measurements in the prediction of mortality and cardiovascular events [22, 23]. The abnormalities seen in the postprandial period in lipid and carbohydrate metabolism in those with insulin resistance provide a pathophysiologic basis for such greater predictive ability. The associations observed with post-load glycaemia, but not with fasting, might suggest that 
alterations in the postprandial metabolism are responsible for the "thrifty" characteristics.

In conclusion, in Brazil, a developing society with a quite heterogeneous population in which women currently of childbearing age were often exposed to undernourishment and frequent infections in their fetal and early neonatal lives, short stature is associated with gestational diabetes, principally in women with greater fat mass. This difference in glycaemic level is present postprandially, but not in the fasting state.

Acknowledgements. This study received partial financial support from the Brazilian Ministry of Health, the National Council for Scientific and Technological Development (CNPq), the Foundation for the Support of Research of the State of Rio Grande do Sul (FAPERGS), the Pan American Health Organization (PAHO) and the Bristol-Myers Squibb Foundation. Additional support was received from Becton-Dickinson, Bayer of Brazil, and Biobrás.

We would like to acknowledge the participation of the following organisations and people in the development of this study: Brazilian Ministry of Health: R. B. Barbosa, L. P. Lima and E. R. Ortiz; Central Project Coordination: M. I. Schmidt, A. J. Reichelt, L. Branchtein, M. C. G. Matos, S. Mengue, I. A. Relian and B.B. Duncan; Quality Control Committee: L. Iochida, L. J. Franco and E. Russo; Porto Alegre Centre: A.J. Reichelt, L. Branchtein and M. C. G. Matos; Salvador Centre: J.M.D. Pousada, M.M.S. Britto and D. Barata; São Paulo Centre: T. Yamashita and C. Nogueira; Rio de Janeiro Centre: E.R.S. Spichler and C. Martins; Manaus Centre: M.M. Teixeira and M.C.T. da Costa; Fortaleza Centre: A. Costa e Forti and E.F. de Paula Pessoa.

\section{References}

1. Brown DC, Byrne CD, Clark PMS et al. (1991) Height and glucose tolerance in adult subjects. Diabetologia 34:531-533

2. Jarrett RJ (1992) Height and glucose tolerance. Diabetologia 35: 191-192

3. Jang HC, Min HK, Lee HK, Cho NH, Metzger BE (1998) Short stature in Korean women: a contribution to the multifactorial predisposition to gestational diabetes mellitus. Diabetologia 41: 778-783

4. Anastasiou E, Alevizaki M, Grigorakis SJ, Philippou G, Kyprianou M, Souvatzoglou A (1998) Decreased stature in gestational diabetes mellitus. Diabetologia 41: 997-1001

5. Lohman TG, Rohe AF, Martorell R (1988) Anthropometric Standardization Reference Manual. Human Kinetics Books, Champaign

6. World Health Organization (1994) Prevention of diabetes mellitus: report of a WHO Study Group. WHO Technical Report Series No 844, World Health Organisation, Geneva
7. Trinder P (1969) Determination of glucose in blood using glucose oxidase with an alternative glucose acceptor. Ann Clin Biochem 6: 24-27

8. Alberti KGMM, Zimmet PZ (1998) Definition, diagnosis and classification of diabetes mellitus and its complications. Part 1: diagnosis and classification of diabetes mellitus provisional report of a WHO consultation. Diabet Med 15: 539-553

9. Norusis MJ (1986) SPSS/PC + Advanced Statistics for the IBM PC/XT/AT. SPSS Inc, Chicago

10. Graham GG, Adrianzen B, Rabold J, Mellits ED (1982) Later growth of malnourished infants and children. Comparison with 'healthy' siblings and parents. Am J Dis Child 136: $348-352$

11. Hales CN, Barker DJ (1992) Type II (non-insulin-dependent) diabetes mellitus: the thrifty phenotype hypothesis. Diabetologia 35: 595-601

12. Law CM (1996) Fetal and infant influences on non-insulindependent diabetes mellitus (NIDDM). Diabet Med 13 [9 Suppl 6]: S49-S52

13. Dungar DB, Ong KK, Huxtable SJ et al. (1998) Association of the INS VNTR with size at birth. Nat Genet 19: 98-100

14. Terauchi Y, Kubota N, Tamemoto H et al. (2000) Insulin effect during embryogenesis determines fetal growth: a possible molecular link between birth weight and susceptibility to type 2 diabetes. Diabetes 49: 82-86

15. Neel JV (1962) Diabetes mellitus: a 'thifty' genotype rendered detrimental by 'progress'? Am J Hum Genet 14: 353-362

16. Groop LC, Tuomi T (1997) Non-insulin-dependent diabetes mellitus - a collision between thrifty genes and an affluent society. Ann Med 29: 37-53

17. Reaven GM (1998) Hypothesis: muscle insulin resistance is the ('not-so') thrifty genotype. Diabetologia 41: 482-484

18. Hales CN, Barker DJ, Clark PM et al. (1991) Fetal and infant growth and impaired glucose tolerance at age 64 . BMJ 303: 1019-1022

19. McKeigue PM, Lithell HO, Leon DA (1998) Glucose tolerance and resistance to insulin-stimulated glucose uptake in men aged 70 years in relation to size at birth. Diabetologia 41: $1133-1138$

20. Crowther NJ, Cameron N, Trusler J, Gray IP (1998) Association between poor glucose tolerance and rapid post natal weight gain in seven-year-old children. Diabetologia 41: $1163-1167$

21. Ravelli AC, Van Der Meulen JH, Michels RP et al. (1998) Glucose Tolerance in adults after prenatal exposure to famine. Lancet 351: 173-177

22. The DECODE Study Group, European Diabetes Epidemiology Group (1999) Glucose tolerance and mortality: comparison of WHO and American Diabetes Association diagnostic criteria. Lancet 354: 617-621

23. Shaw JE, Hodge AM, Courten M, Chitson P, Zimmet PZ (1999) Isolated post-challenge hyperglycaemia confirmed as a risk factor for mortality. Diabetologia 42: 1050-1054 